\title{
Processing and Recycling of thermoplastic polymers: Current Scenario and Future Challenges
}

\author{
Balwant Singh ${ }^{1}$, Raman Kumar ${ }^{2}$, Jasgurpreet Singh Chohan ${ }^{3}$ \\ ${ }^{1}$ Assistant Professor and Research Scholar, Department of Mechanical Engineering, Chandigarh \\ University,Mohali, 140413, India. \\ ${ }^{2}$ Associate Professor, Department of Mechanical Engineering, Chandigarh University,Mohali, 140413, India. \\ Article History: Received: 11 January 2021; Accepted: 27 February 2021; Published online: 5 April 2021
}

\begin{abstract}
Thermoplastic polymers are extensively utilized in electronics, aerospace, automobile and additive manufacturing industries due to low cost, low temperature processing and reusability. Thermoplastics of different grades and chemical structures arereadily available in the market They can be reusedand reshaped, and also can be manufactured with less weight proportion as compared to the metals and ceramics by providing same strength of material. As a result, the plastics products in the market are getting popular day by day with high demand of customized products due to inception of additive manufacturing technologies. In any case, the issue of recycling these materials is challenge due to enormous energy requirements and varying chemical composition of different polymers. There are both mechanical and financial issues that restrict the advancements in this field. The recycling process of polymers can be done by the four different ways such as primary recycling process, secondary recycling process, tertiary recycling process and quaternary recycling process which can be discussed in this systematic review with practical examples. The modifications and implementation of these polymer waste recycling techniques could help to reduce wastage and save material cost which would directly affect the economy of contemporary industries.
\end{abstract}

Keywords:Polymers; Recycling Processes; Properties; thermoplastics

\section{Introduction}

The creation of new polymers has been directly connected with recycling of the polymers after usage which means properties of the polymers have been checked according to first time use and then the benefits obtained after using one time by doing recycling processes. A slower improvement inside the field of reusing makes a significant issue: huge amounts of utilized polymeric materials are being disposed of consistently. It prompts environmental and therefore social issues[1]. Earlier the used polymers was dumped under the oceans during 90's but after 1990 the government denied to dumping process of the polymers due to which the recycling demand of the polymers has been increasing rapidly in the market[2]. If the polymers are not in recycling use in the future so it means, there is continuously degradation of the polymers from the cycle of economy. So, overall the recycling process plays a vital role which can help economically to maintain the prices of reuse polymers in the market, helps to improve the pollution from the environment as the re-usage of the polymers, and improve the social issues. Nowadays, the additional worth made by reusing is likewise fairly low; therefore, a lot of utilized plastics and manufactured materials can be just incompletely come back to the financial cycle[3]. The recycling process for the ceramic and metals are easy as compared to polymers because by reusing the ceramics and metals mostly the same properties can be obtained but in polymers its hard to maintain the same properties after recycling process. So, the various recycling processes and experiments are going in the market to get better results after the recycling of the polymers. The recycled polymers can be the highest demand for the textile and the plastic industries and also used in energy and fuel industries in the coming years. The waste materials after the first usage have been divided into three parts basically named as post- customer, end of waste and end of live. End of waste means when the materials can use for recycling process while when the materials are within production. Post- customer and End of live means when the polymers are recycled after the lifecycle of the product like materials used of packaging, materials used for making mobile phones, computers, televisions and many household devices. The recycling processes can be done according to the properties have to obtained after that in which various purification methods and sorting methods can be used to get the better outputs from the recycled materials. The mechanical recycling process and chemical recycling process is the highest demandable recycling method in the market. The situations in a lifecycle of an item and its manufacture are illustrated in figure 1 and their important properties are summed up in Table 1. Maximal decrease of utilization of nonrenewable materials and the vitality in items and procedures, just as tough enhancement of utilization of vitality sources and fuel, stay significant difficulties for our general public. The motivation behind this paper is to 
give a preview of important social turns of events and market advancements, and innovative work exercises in the field of reusing[4].

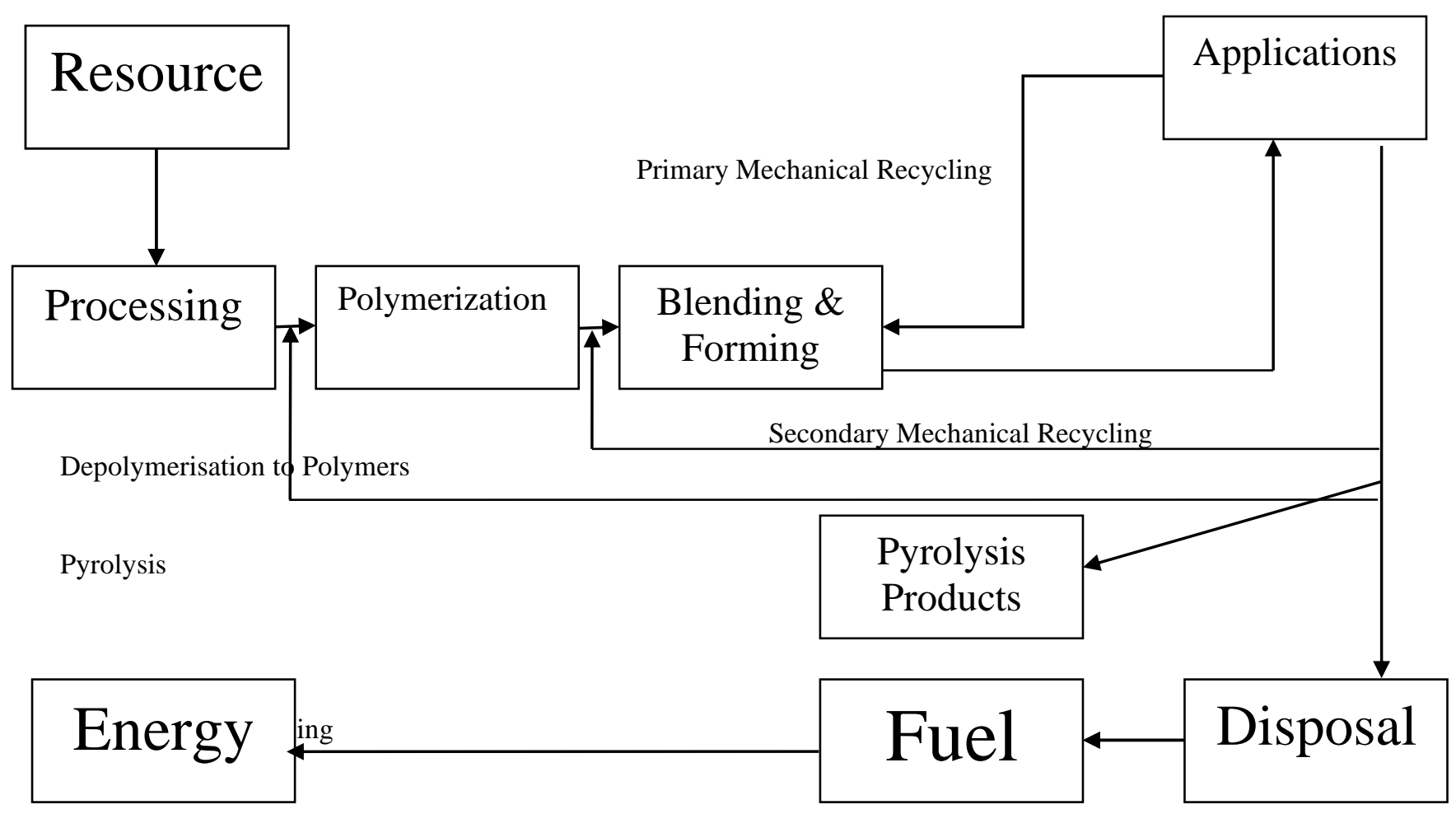

Fig. 1 Position of Different Recycling Processes in the Lifecycle

Table 1 Properties obtained by using different Recycling Processes

\begin{tabular}{|c|c|c|}
\hline Waste Material Inputs & Recyling Process & Results \\
\hline $\begin{array}{l}\text { Post customer, End of Watse } \\
\text { and End of Live }\end{array}$ & $\begin{array}{l}\text { Collection of Material and } \\
\text { Preparation of it }\end{array}$ & $\begin{array}{l}\text { Recycling Input and Material } \\
\text { and Energy should be Recovered. }\end{array}$ \\
\hline End of Waste & Primary Recycling Process & Product is semi ready \\
\hline End of Live and Post Customer & Secondary Recycling Process & Product is semi ready \\
\hline $\begin{array}{l}\text { Post customer, End of Watse } \\
\text { and End of Live }\end{array}$ & Tertiary Recycling Process & $\begin{array}{l}\text { Product is in Chemical forms } \\
\text { such as Gases, Liquids and Solids }\end{array}$ \\
\hline $\begin{array}{l}\text { Post customer, End of Watse } \\
\text { and End of Live }\end{array}$ & Quaternary Recycling Process & $\begin{array}{l}\text { Final Products are electricity, } \\
\text { heat or steam }\end{array}$ \\
\hline
\end{tabular}

\section{Recycling Methods}

Recycling of the composites can be done by basically three ways named as mechanical, chemical and thermal. The different ways to do the recycling of material has been shown in the following figure 2 .

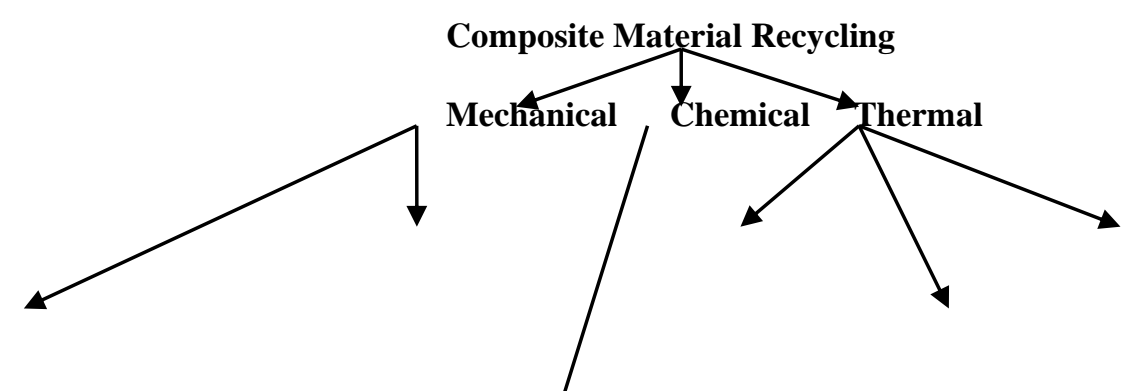




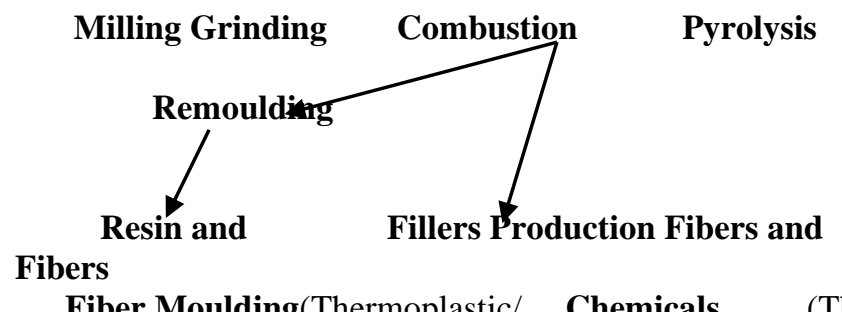

Fiber Moulding(Thermoplastic/ Chemicals (Thermoplastic/(Thermoplastic/Chemicals (Thermoplastic only) Thermosetting) (Thermoplastic/ Thermosetting)Thermosetting) Thermosetting)

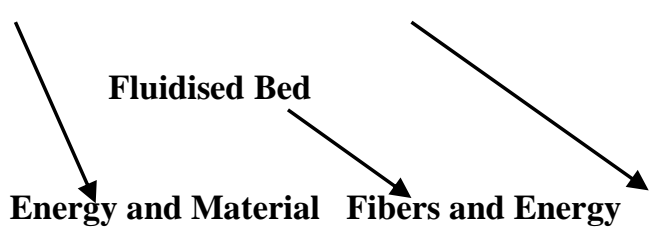

(Thermoplastic/

Thermosetting)

Fig. 2 Types of Recycling Method

\subsection{Thermoplastics Primary Mechanical Recycling}

Primary recycling means when the polymers are directly used after the first usage without any change of properties in the product. Thermoplastics primary recycling has been mostly utilized by the first user only from the industrial waste[5]. Thermoplastic Primary Recycling process also called as closed loop process because there are very less changes in the properties done after this process and no external method implemented on it. Primary recycling process is one of the most difficult process and not much popular recycling process in the market because mostly the sorting of the materials can be done manually which may be most costly to get the specific properties for the particular requirements[6]. The final product in the primary recycling process can also be done by grinding process in which one time used material can be blend out with different polymers to get the fine properties from the final product. After grinding, mixing or milling process the material should be purifies with one or two different steps to get the fine properties in the final product[7]. Primary recycling can also be done by melting the material and recycled for the use of new purpose by enhancing some properties of the material according to the requirements and the different mechanical methods which are commonly used named as molding process done by injection process, molding done by rotators, heat pressing and hot extruding process[8]. Primary mechanical recycling process is also named as Closed Loop Processing technique because of the following reasons[9]:

- $\quad$ disposed of materials are incorporated rapidly once more into the creation cycle

- $\quad$ waste material can be easily removed directly from the products

- $\quad$ polymers after primary process can perform under high temperatures very effectively

- $\quad$ after primary recycling the final product can work same as properties of the fresh product

The best example of the primary mechanical recycling process is the recycling of the Television back covers which comprised of mixes of polycarbonate with acrylonitrile butadiene styrene with phosphor-based fire retardants were changed over into fresh back covers of the television[10].

\subsection{Thermoplastics Secondary Mechanical Recycling}

Secondary Mechanical Recycling is the method of recycling in which the proper separation and purification of the material can be done as compared to primary recycling process. In secondary recycling process other than thermoplastic polymers can also be reprocessed while in the primary recycling only thermoplastic material can be recycled. In the secondary recycling process the polymers of the materials cannot displaced from their positions but the weight of the molecules falls down and it forms a chain like structure with the help of different chemicals or water[11]. The final product after secondary recycling process obtained having poor mechanical properties because of the mixture of polymers in the matrix materials like an example poly(ethylene terephthalate) mixed with poly vinyl chloride decreased the mechanical properties of the final product after recycling process. The material separation during the recycling process can be done before making any new material in the secondary recycling process. Infrared spectroscopy can be used to recognize the type of polymer present in the material. Optical color machine can be used to differentiate the crystal clear materials and the colored materials from each other. Laser sorting technique is using now a days to separate the various electrical components from the scrap and also to differentiate the various kinds of plastics presents in the waste materials[12]. The new technology named as electrostatic detection can also be used to find out the useful 
materials from the waste material. In primary recycling process there is no purification done before recycling process whereas the secondary recycling processes have various properties which has been discussed below[13]:

- Waste materials after recycling also can be available for various different uses.

- $\quad$ Any shape can be formed after recycling

- Complex structures can be manufactured after recycling which can withstand with various different range of temperatures.

- $\quad$ Recycled material is not much costlier as like fresh material.

- Availability if different range of prices of materials.

- Beneficial for social and economical aspects.

In the secondary recycling process mostly used to form the new car products from the scrap of the cars hence after the secondary recycling process it does not obtained the good quality materials as like the fresh material. It has been concluded that when the material after the secondary recycling process become so costly then it can be converted $\mathrm{n}$ some fuel for the different uses in our society. Papaspyrides et al. utilized industrially accessible settling added substances (e.g., Recyclossorb 550) to save the chain length in the closed-loop recycling process of post-purchase surges of polypropylene (PP) and high-thickness polyethylene (HDPE). These added substances contain cancer prevention agents and different other settling parts. Especially promising outcomes were accomplished in the reuse of HDPE bottle boxes[14].Arkan et al. have exhibited the viability of this methodology for mixes of low-thickness polyethylene (LDPE), HDPE, PP, polystyrene (PS), PVC, and PET under the proper scaling of the lab. They utilized xylene, toluene, dichloromethane, and benzyl liquor as solvents and n-hexane and methanol as with the non-solvents[15].

\subsection{Thermoplastics Tertiary Mechanical Recycling}

Tertiary recycling processes are that type of process in which the polymers are in the form of chain structure can be reformed in the small molecular structure by using the different chemical processes and some of the examples of that are pyrolysis structures, hydrolysis structures, gasification and hydrocracking[16]. The products which are in used while during the conversion of chain like structure polymers into the small molecular are mostly in the form of liquids or in gaseous form[17]. The governments gives the subsidies on the tertiary recycle processed to the industries because with the help of this kind of process low price of final material can be achieved with high range of properties[18].Polymers shaped through polycondensation responses (Figure 3), for example, polylactic acid (PLA), poly(ethylene terephthalate), and polyurethanes, can be productively depolymerized; in this way, the acquired monomers can be reused to combine the fresh polymers [19]. Panda and Singh did the research to find out the fuels like diesel, gasoline and kerosene by using the different chemical from the waste materials of polypropylene with the pyrolysis process by taking a kaolin clay material which act as a catalyst material in it. The maximum amount of oil extracted from the polypropylene process was 85\% [20]. Vicente et al. performed an experiment on high density polyethylene to examine the cracking come due to thermal changes at $400^{\circ} \mathrm{C}$ by using the phenol in it which improves the chain reactions and the main products are obtained from this chemical process are olefins[3]. Zhuo and Levendis analyzed the formation of nanotubes with the help of polymer waste in the tertiary recycling process. It has been observed that exact amount of catalyst was required under the pyrolyzed process at proper suitability conditions. The materials obtained after this process used in electronic industry, biotechnology industry in the form of nanotubes[21].
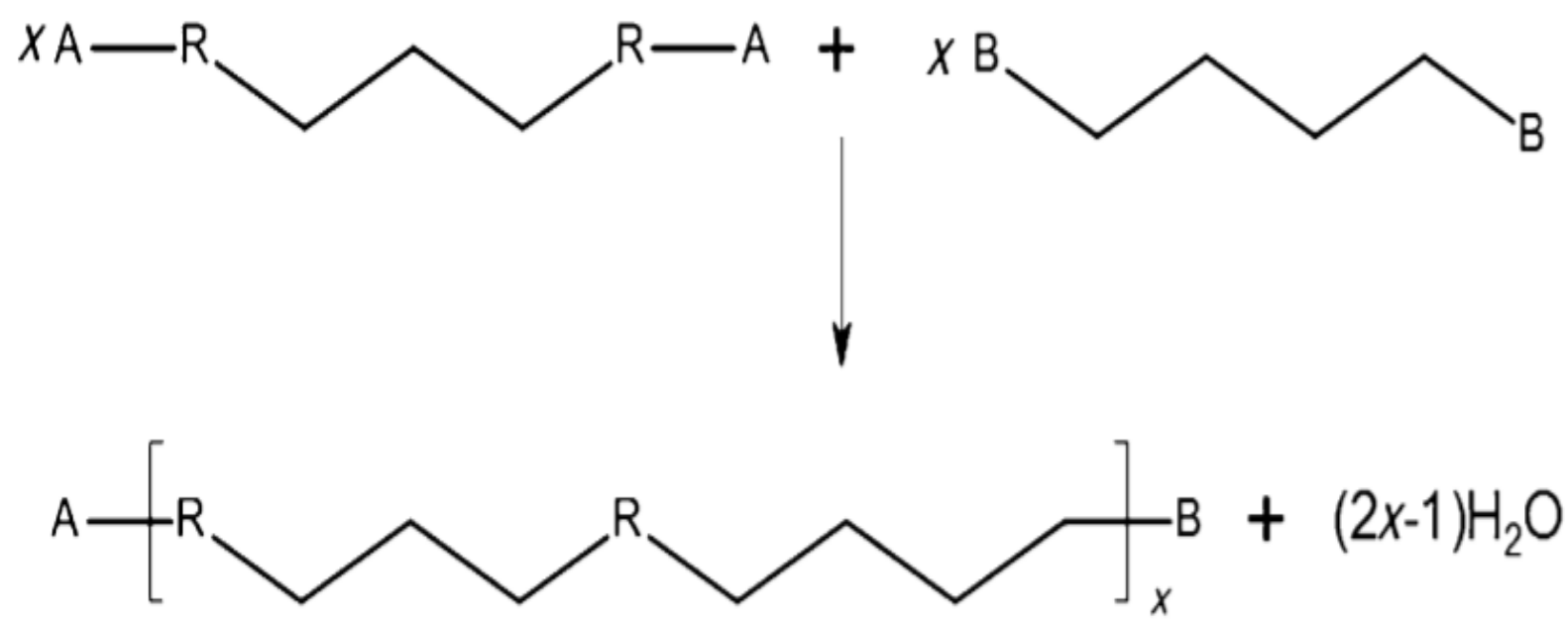
Fig. 3Polycondensation Process[19]

Polyurethanes have a property for producing the amines and polyols as shown in the figure 4 . The amines and polyols is act as a fuel to produce the new materials after the recycling in the form of polyurethanes but the hydrolysis of the polyurethanes cannot be used for the recycling process because it is very much expensive as compared to polyols and amines[22].<smiles>[Z10]OC(=O)N[Y]N([R])C(=O)O[R]</smiles>

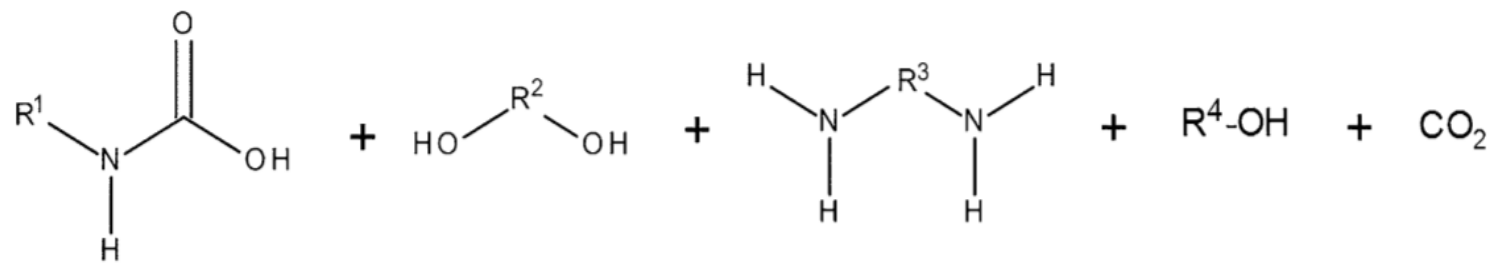

Fig. 4 Hydrolysis process of Polyurethanes[22]

Glycolysis of Polyurethanes is the best process to recover the polyols in the Polyurethanes synthesis has been

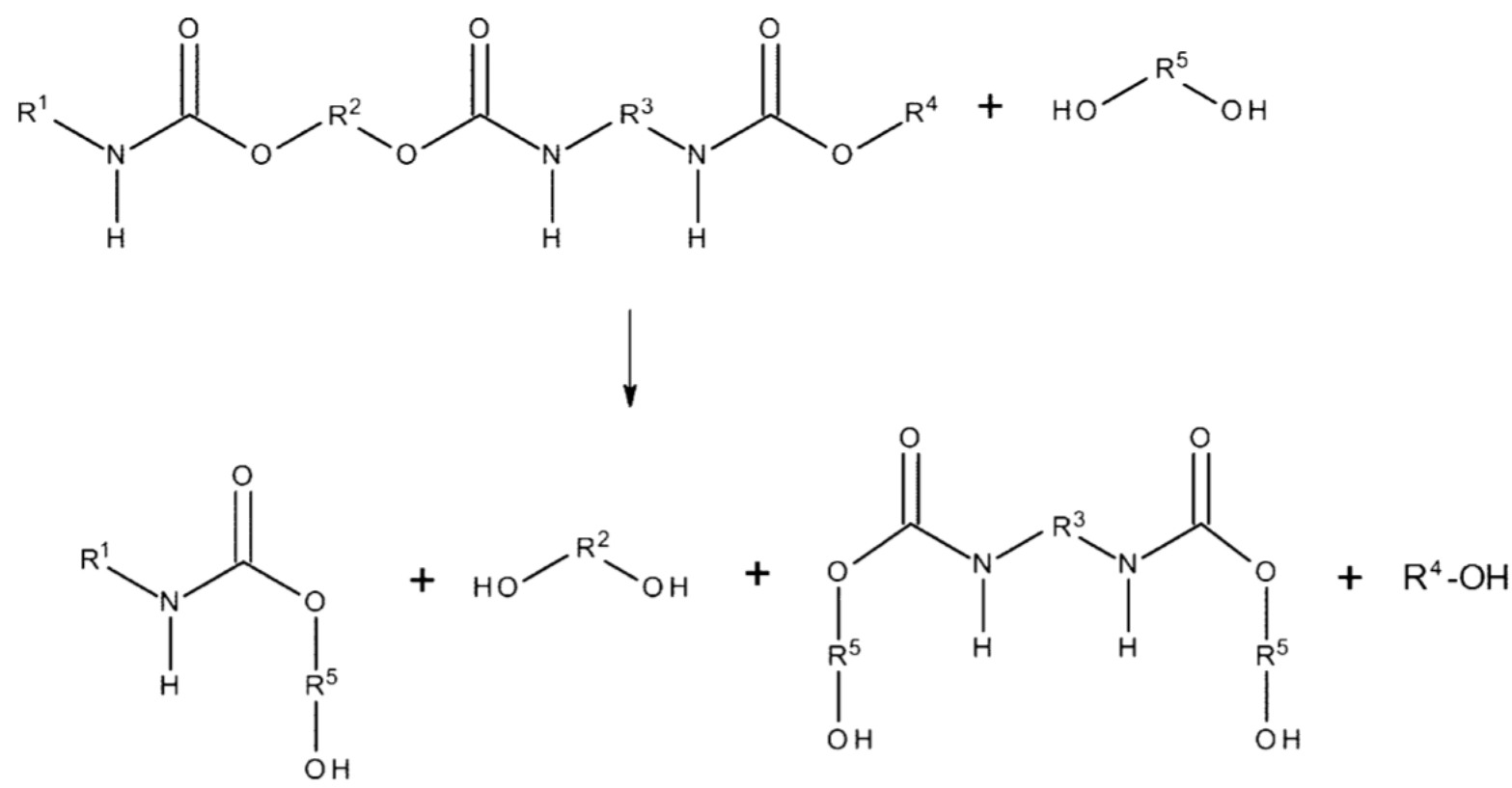

shown in figure 5 . This reaction can be done only when the temperature range is above than $200^{\circ} \mathrm{C}$. This glycolysis process is the most famous process in the recycling processes because of its best recovery within short period of time[23].

Fig. 5 Glycolysis of Polyurethanes[23] 


\subsection{Thermoplastics Quaternary Mechanical Recycling}
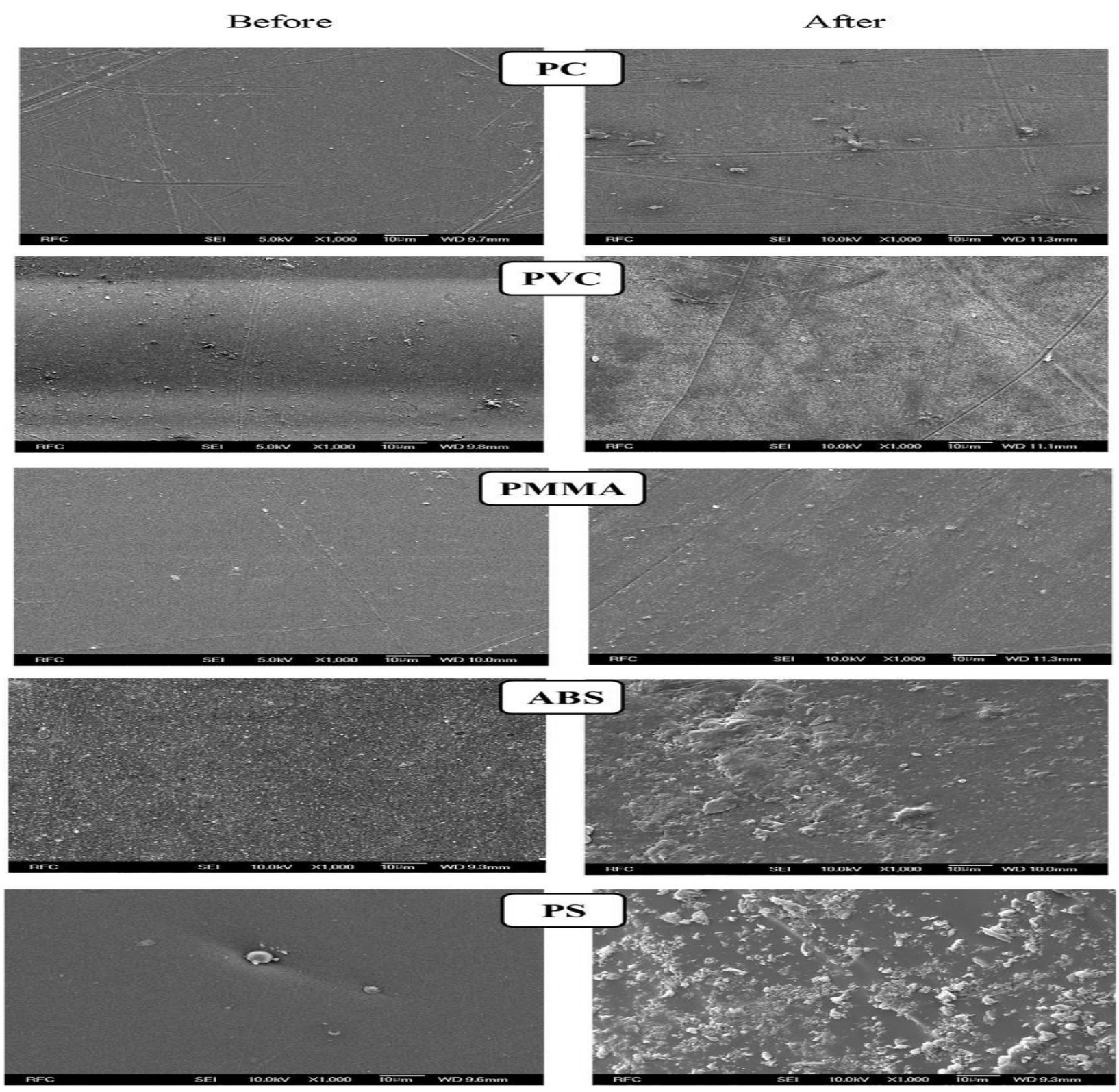

Fig. 6 SEM images of PolycarbonatePoly-Vinyl Chloride, Poly(methyl methacrylate), , Acrylonitrile butadiene styrene, Polystyrene

Quaternary recycling method is that type of method in which the energy of the materials can be reformed[24]. Quaternary recycling method is a well-known strategy for vitality recovery[25]. This technique is particularly utilized for handling of blended and vigorously sullied squanders, which can't be effective as well as monetarily reused by some other technique. Consuming of vitality thick waste can make warmth, power, or different types of vitality, which can be legitimately utilized in innovative procedures or for warming of structures[5]. Quaternary reusing diminishes volume fraction of the waste materials to generally $0.8 \%$ of the underlying volume and decays harmful and infectious waste. It is along these lines perfect for the reusing of clinical applications and bundling of perilous products. Inorganic constituents are changed over to inactive slag through burning and can be utilized for the development of streets[14]. Different arrangements and techniques are utilized to use the quaternary recycling process. The waste materials came out from plastics can be utilized as a vitality thick fuel for processes that run at high peak temperatures, the estimated value of the calorific of this process is basically engineered polymers which are mostly higher than that of coal temperature[26].The materials which can be manufactured with the help of this process are used for making cement furnaces in the industries 
because it can withstand with high temperatures.Chung et al. done experiment an intriguing way to deal with decreasing the arrangement of 1,2-dichlorobenzene, Carbon mono oxide, and conceivably dioxins, which take after substance structure and poisonousness of the previous one, by abusing the synergistic impact among Titanium and Iron: through the expansion of Iron Oxide nanoparticles secured with a permeable layer of $\mathrm{TiO} 2$ into PE or PS followed by burning in a pressed bed reactor fundamentally less harmful gasses were identified after the preparing within the sight of the blended impetus in contrast with iron oxide and titanium oxide alone or no implanted particles in the polymers[27].

SEM images of the various materials like Poly-Vinyl Chloride, Poly(methyl methacrylate), Polycarbonate, Acrylonitrile butadiene styrene, Polystyrenebefore and after the different thermoplastic and thermosetting mechanical recycling processes has been shown in the following figure 6 .

\section{Survey in Market for Different Recycled Materials}

In this survey it has been possessed out that all the manufacturing industries are trying to find out the different ways to reuse or recycle the materials. Significant variables among others are the accessibility of materials, coordination's and framework, vitality utilization, and enactment[28]. In this survey model, we will examine monetary parts of included markets and some other applicable subjects.

\subsection{An overview on the Polymer Market}

The polymer used in different industries throughout the world is like $65 \%$ of polymers were used by thermoplastics industries, $13 \%$ of polymers used by the textile industries and $4 \%$ by glue industries and near $24 \%$ of polymers are manufactured by the European countries. The packaging industries used $41 \%$ of reused polymers, $20 \%$ by construction industries and $13 \%$ by textile industries. The polymers basically have the electrical and thermal properties which can also withstand for high temperatures which can be used in making the products of automobile industries, electronics industries, making turbines and in construction industries. It has been observed hat fresh polymers have much better properties as compared to the recycled ones but the recycled polymers are low in price as compared to virgin polymers which is the biggest factor to boost up the sale of the reused polymers. The price of the fresh polymers are actually directly proportional to the prices of fuels which was continuously increasing from the last few decades[12].Another subtlety as the referenced is that the mixture of at least two polymers framing a waste stream can prompt the presence of a beneficial blend of properties or potentially new properties, which is available in the introductory material[29].Additionally, data about accessibility, quality, and supportability of reused polymers can likewise play a huge role. This positive pattern may proceed into the future with the assistance of R\&D: mechanical advancement may diminish reusing costs through advances in process productivity and huge upgrades in the nature of reused materials [30]

\subsection{Materials used for Packaging}

Packaging materials are the biggest consumption of the reused or recycle polymers around $40 \%$ consumption done by the packaging all over the world. The polyolefines and polyethylene are the most packaging material used in the industries to manufacturing the bottles, bags and various things which have only two to three months validity[31]. In numerous nations, plastic packaging materials are gathered independently from the remainder of the waste. In the greater part of the holder parks, there are additionally extraordinary frameworks for hard plastics, foils, and Styrofoam.The use of recyclates for food packaging is somewhat restricted in view of highsecurity prerequisites: poisonous synthetic compounds can be consumed into the polymers and diffuse later into the food. Nonetheless, reused polymer parts that have not come into direct contact with food can even now be utilized[32].

\subsection{Materials used for Constructions}

Materials used for the construction are the second biggest consumer of the polymers around $20 \%$ consumption done by the construction industries. Materials like construction pipes, water tanks, carpets are come under this section and this type of material has been manufactured according to the 10 to 12 years' time span of life so it is mainly eco-design recycled polymers which can be used for long terms. Now a days Poly Vinyl chloride is the most famous polymer in the construction market for the decoration purposes, under-ceiling purposes and many more[33].

\subsection{Materials used in Textile Industries}

Materials used in Textile industries are the third largest consumer of polymers around $13 \%$ consumption done by textile industries and it is continuously growing within coming few years because of the higher demand of the synthetic fibers in the market. As, we know that the wool carpets which was used earlier in the houses has 
been replaced with the polypropylene polymers. Also the polypropylene polymers are used in manufacturing the raincoats, materials used for making umbrellas[34].

\section{Challenges and Future Scope}

The wastage of the materials obviously will be increased in the future as the population of the world increase and even more the comfort zone level of the people continuously increasing day by day due to which usage of polymers also will increase in the future coming years. Polymers have continuously been used in making materials of wood, glass, metal, and plastics[32]. The plastics business has been hampered by the worldwide downturn in 2008, yet consistent the development has been distinguished since 2009. The pace of reusing of polymers is required to display a pattern like their creation[35]. Current patterns uncover that guidelines to decrease dumping at the ocean has been generally effective. Notwithstanding, the rising interest for plastics is relied upon to prompt a compounding of the existing circumstance with a huge increment in plastic usage volume foreseen to happen even in the profound sea. Therefore, an inventive arrangement is required for the test of the product assortment and reuse of polymeric waste from the seas. Still there are many areas in which recycled product can be used to save our environment for which many researchers presently work on the biodegradable polymers and also research is going on the anti toxic polymers made from natural polymers [36]. The mixed plastics catalyst polymers recycling process is the latest topic on which researchers are working to get the better outputs.

Research and development exercises are required to turn around this expanding waste issue. They ought to incorporate enormous scope tests and cautious construction industry investigations. More consideration must be paid additionally to less-preferred to strategies, for example, radiation techniques, compatibilization, crossconnecting, and utilization of ionic fluids. The last ones are required to turn out to be fundamentally more monetarily appealing in the event of their more extensive mechanical application what's more, effective re-use in the future. As a rule, the utilization of lab-based strategies may prompt the improvement of new startling and yet useful answers for the recycling processes for the different industries.

\section{Conclusions}

Thermoplastic polymers play an important role in functional, smart and $4 \mathrm{~d}$ material applications in addition to additive manufacturing industry. The excellent mechanical properties, wear resistance, toughness with lower melting temperatures make them suitable for low temperature extrusion and molding for rapid prototyping applications. The present review highlights different types of polymer recycling techniques such as primary recycling, secondary recycling, tertiary recycling and quaternary recycling. The chemical process along with changes in material properties after each recycling process are discussed in detail. Afterwards future challenges and scopr for further research is elaborated.

\section{Refereneces}

1. K. M. Zia, H. N. Bhatti, and I. Ahmad Bhatti, "Methods for polyurethane and polyurethane composites, recycling and recovery: A review," React. Funct. Polym., vol. 67, no. 8, pp. 675-692, 2007, doi: 10.1016/j.reactfunctpolym.2007.05.004.

2. D. K. A. Barnes, F. Galgani, R. C. Thompson, and M. Barlaz, "Accumulation and fragmentation of plastic debris in global environments," Philos. Trans. R. Soc. B Biol. Sci., vol. 364, no. 1526, pp. 1985-1998, 2009, doi: 10.1098/rstb.2008.0205.

3. G. Vicente, J. Aguado, D. P. Serrano, and N. Sánchez, "HDPE chemical recycling promoted by phenol solvent," J. Anal. Appl. Pyrolysis, vol. 85, no. 1-2, pp. 366-371, 2009, doi: 10.1016/j.jaap.2008.10.007.

4. M. K. Gupta et al., "Parametric optimization and process capability analysis for machining of nickel-based superalloy," Int. J. Adv. Manuf. Technol., vol. 102, no. 9-12, pp. 3995-4009, Jun. 2019, doi: 10.1007/s00170-019-03453-3.

5. S. M. Al-Salem, P. Lettieri, and J. Baeyens, "The valorization of plastic solid waste (PSW) by primary to quaternary routes: From re-use to energy and chemicals," Prog. Energy Combust. Sci., vol. 36, no. 1, pp. 103-129, 2010, doi: 10.1016/j.pecs.2009.09.001.

6. C. Baillie, D. Matovic, T. Thamae, and S. Vaja, "Waste-based composites - Poverty reducing solutions to environmental problems," Resour. Conserv. Recycl., vol. 55, no. 11, pp. 973-978, 2011, doi: 10.1016/j.resconrec.2011.05.006.

7. V. Goodship, "Plastic recycling," Sci. Prog., vol. 90, no. 4, pp. 245-268, 2007, doi: 
$10.3184 / 003685007 X 228748$

8. C. C. Kao, O. R. Ghita, K. R. Hallam, P. J. Heard, and K. E. Evans, "Mechanical studies of single glass fibres recycled from hydrolysis process using sub-critical water," Compos. Part A Appl. Sci. Manuf., vol. 43, no. 3, pp. 398-406, 2012, doi: 10.1016/j.compositesa.2011.11.011.

9. S. Kumar, M. Kumar, and A. Handa, "Combating hot corrosion of boiler tubes - A study," Eng. Fail. Anal., vol. 94, pp. 379-395, Dec. 2018, doi: 10.1016/j.engfailanal.2018.08.004.

10. Lalita, A. P. Singh, and R. K. Sharma, "Synthesis and characterization of graft copolymers of chitosan with NIPAM and binary monomers for removal of $\mathrm{Cr}(\mathrm{VI}), \mathrm{Cu}(\mathrm{II})$ and $\mathrm{Fe}(\mathrm{II})$ metal ions from aqueous solutions," Int. J. Biol. Macromol., vol. 99, pp. 409-426, 2017, doi: 10.1016/j.ijbiomac.2017.02.091.

11. A. Dobry and F. Boyer-Kawenoki, "Phase separation in polymer solution," J. Polym. Sci., vol. 2, no. 1, pp. 90-100, 1947, doi: 10.1002/pol.1947.120020111.

12. J. Hopewell, R. Dvorak, and E. Kosior, "Plastics recycling: Challenges and opportunities," Philos. Trans. R. Soc. B Biol. Sci., vol. 364, no. 1526, pp. 2115-2126, 2009, doi: 10.1098/rstb.2008.0311.

13. P. Gairola, S. P. Gairola, V. Kumar, K. Singh, and S. K. Dhawan, "Barium ferrite and graphite integrated with polyaniline as effective shield against electromagnetic interference," Synth. Met., vol. 221, pp. 326-331, 2016, doi: 10.1016/j.synthmet.2016.09.023.

14. C. N. Kartalis, C. D. Papaspyrides, and R. Pfaendner, "Closed-loop recycling of postused PP-filled garden chairs using the restabilization technique. III. Influence of artificial weathering," J. Appl. Polym. Sci., vol. 89, no. 5, pp. 1311-1318, 2003, doi: 10.1002/app.12261.

15. A. J. Hadi, G. F. Najmuldeen, and I. Ahmed, "Polyolefins Waste Materials Reconditioning Using Dissolution/Reprecipitation Method," APCBEE Procedia, vol. 3, no. May, pp. 281286, 2012, doi: 10.1016/j.apcbee.2012.06.083.

16. A. Brems, J. Baeyens, and R. Dewil, "Recycling and recovery of post-cet alonsumer plastic solid waste in a European context," Therm. Sci., vol. 16, no. 3, pp. 669-685, 2012, doi: 10.2298/TSCI120111121B.

17. K. M. Batoo et al., "Structural, morphological and electrical properties of $\mathrm{Cd} 2+$ doped MgFe2-xO4 ferrite nanoparticles," J. Alloys Compd., vol. 726, pp. 179-186, 2017, doi: 10.1016/j.jallcom.2017.07.237.

18. M. Patel, N. Von Thienen, E. Jochem, and E. Worrell, "Recycling of plastics in Germany," Resour. Conserv. Recycl., vol. 29, no. 1-2, pp. 65-90, 2000, doi: 10.1016/S09213449(99)00058-0.

19. G. S. A. N. Miguel, U. Rey, and J. Carlos, "European trends in the feedstock recycling of plastic wastes," Glob. NEST JournalGlobal NEST Int. J., vol. 9, no. 1, pp. 12-19, 2018, doi: 10.30955/gnj.000432.

20. A. Panda, "Studies on process optimization for production of liquid fuels from waste plastics," Chem. Eng. Dep. Natl. Inst. Technol. Rourkela, no. July 2011, 2011.

21. C. Zhuo and Y. A. Levendis, "Upcycling waste plastics into carbon nanomaterials: A review," J. Appl. Polym. Sci., vol. 131, no. 4, pp. 1-14, 2014, doi: 10.1002/app.39931.

22. X. Li, J. Wang, M. Kang, Y. Zhao, Q. Li, and C. Liang, "Preparation of green waterborne polyurethane with improved hydrolysis repellency from $\mathrm{CO} 2$ derived amino-alcohol," Eur. Polym. J., vol. 127, no. February, p. 109571, 2020, doi: 10.1016/j.eurpolymj.2020.109571.

23. R. Esquer and J. J. García, "Metal-catalysed Poly(Ethylene) terephthalate and polyurethane degradations by glycolysis," J. Organomet. Chem., vol. 902, p. 120972, 2019, doi: 10.1016/j.jorganchem.2019.120972.

24. A. Schnürer and J. Schnürer, "Fungal survival during anaerobic digestion of organic household waste," Waste Manag., vol. 26, no. 11, pp. 1205-1211, 2006, doi: 10.1016/j.wasman.2005.09.007.

25. M. S. Hossain, A. Santhanam, N. A. Nik Norulaini, and A. K. M. Omar, "Clinical solid waste management practices and its impact on human health and environment - A review," Waste Manag., vol. 31, no. 4, pp. 754-766, 2011, doi: 10.1016/j.wasman.2010.11.008. 
26. G. Davis and J. H. Song, "Biodegradable packaging based on raw materials from crops and their impact on waste management," Ind. Crops Prod., vol. 23, no. 2, pp. 147-161, 2006, doi: 10.1016/j.indcrop.2005.05.004.

27. J. S. Choi, H. K. Youn, B. H. Kwak, Q. Wang, K. S. Yang, and J. S. Chung, "Preparation and characterization of $\mathrm{TiO} 2$-masked $\mathrm{Fe} 3 \mathrm{O} 4$ nano particles for enhancing catalytic combustion of 1,2-dichlorobenzene and incineration of polymer wastes," Appl. Catal. B Environ., vol. 91, no. 1-2, pp. 210-216, 2009, doi: 10.1016/j.apcatb.2009.05.026.

28. S. Pimenta and S. T. Pinho, "Recycling carbon fibre reinforced polymers for structural applications: Technology review and market outlook," Waste Manag., vol. 31, no. 2, pp. 378-392, 2011, doi: 10.1016/j.wasman.2010.09.019.

29. H. Stichnothe and A. Azapagic, "Life cycle assessment of recycling PVC window frames," Resour. Conserv. Recycl., vol. 71, pp. 40-47, 2013, doi: 10.1016/j.resconrec.2012.12.005.

30. A. K. Parlikad and D. McFarlane, "RFID-based product information in end-of-life decision making," Control Eng. Pract., vol. 15, no. 11, pp. 1348-1363, 2007, doi: 10.1016/j.conengprac.2006.08.008.

31. Y. J. Wan, G. Li, Y. M. Yao, X. L. Zeng, P. L. Zhu, and R. Sun, "Recent advances in polymer-based electronic packaging materials," Compos. Commun., vol. 19, no. March, pp. 154-167, 2020, doi: 10.1016/j.coco.2020.03.011.

32. Y. Zhong, P. Godwin, Y. Jin, and H. Xiao, "Biodegradable polymers and greenbased antimicrobial packaging materials: A mini-review," Adv. Ind. Eng. Polym. Res., vol. 3, no. 1, pp. 27-35, 2020, doi: 10.1016/j.aiepr.2019.11.002.

33. Y. Chen, Y. Cui, A. Guimond Barrett, F. Chille, and S. Lassalle, "Investigation of calcite precipitation in the drainage system of railway tunnels," Tunn. Undergr. Sp. Technol., vol. 84, no. October 2018, pp. 45-55, 2019, doi: 10.1016/j.tust.2018.10.021.

34. S. Chakraborty and M. C. Biswas, "3D printing technology of polymer-fiber composites in textile and fashion industry: a potential roadmap of concept to consumer," Compos. Struct., p. 112562, 2020, doi: 10.1016/j.compstruct.2020.112562.

35. A. K. Panda, R. K. Singh, and D. K. Mishra, "Thermolysis of waste plastics to liquid fuel. A suitable method for plastic waste management and manufacture of value added products-A world prospective," Renew. Sustain. Energy Rev., vol. 14, no. 1, pp. 233-248, 2010, doi: 10.1016/j.rser.2009.07.005.

36. M. M. Pang, M. Y. Pun, and Z. A. M. Ishak, "Degradation studies during water absorption, aerobic biodegradation, and soil burial of biobased thermoplastic starch from agricultural waste/polypropylene blends," J. Appl. Polym. Sci., vol. 129, no. 6, pp. 3656-3664, 2013, doi: 10.1002/app.39123. 